\title{
Open the Doors and Let Us Out: Escaping the Coloniality of Racism
}

\author{
Fiona C. Edwards \\ York University \\ fionaedwards9@hotmail.com
}

\begin{abstract}
Racism is an integral part of racialized groups' experiences as Whiteness continues to foster the power and privilege it affords to White people. This has resulted in the racialization of Black bodies inflicted by racism. For Black youth, escaping the coloniality of racism may seem to be an impossible task as racism is ubiquitous, and has been deeply embedded in societal structures for hundreds of years. However, a heightened consciousness of racism provides a platform to fight against racial injustice. Instead of being locked in systems of oppression whereby Black bodies are wounded, there is a movement in the youth population to end intergenerational racist ideologies of what it means to be Black. Open the doors and let us out: Escaping the coloniality of racism empowers Black youth to embrace their Blackness, use their bodies and voices to reconstruct their racial identities and positionalities in society with pride and dignity.
\end{abstract}

Keywords: Black youth, racism, coloniality

Racism is our superior complex shadow

It follows us day and night.

In the day, it illuminates with stereotypes,

Prejudices, and racial discrimination.

At night, our superior complex shadow

Hides behind us

Until the bright lights of its Masters' sirens

Render it visible.

They know us, target us and violate our rights

Just as they did our parents and grandparents.

Every assault, insult, injury and trauma

Produces sores on our racialized bodies and minds.

The sores are too numerous to count.

We wrestle with the assault, insult, injury and trauma

But to no avail

Our bodies are covered entirely with sores. 
As Black youth, we hide behind our tears

The sores are still there.

We hide in the crowd yet we stand out

We cry out loud but our cries are faint

We use our eyes to tell an emotional story

No one cares to look at us.

The pain inflicted by our sores worsen

As they get reinjured

By our superior complex shadow.

Open the doors and let us in

The waiting room is empty

Our sores are too painful.

However, we are not welcomed in

We are a threat, our bodies and race are punitive.

They are not the shape and shade preferred

By the hegemonic power

That oversees our superior complex shadow.

We rid our body of its color

Straightened our hair,

Speak proper Eurocentric English,

Change our name and work hard

To make it half-way in

But the doors remain closed.

Every attempt to make it in

Causes more sores on our racialized body.

The scars are visible, they are permanent, We can't pretend they will go away

As they are constantly appearing and reappearing

When we are at school, on the street and even in our own backyard.

We will not ignore it's not real for us

We live it every day, it is our present and future reality.

We have to break loose from our superior complex shadow

To create a new pathway to let ourselves out not in. 
We are wounded, oppressed, marginalized and racialized.

Our bodies are sore, our minds are still conscious,

Our mouth remains the only part

Of our body that is uninjured.

We speak up but no one listens

We can't silence our voices,

We speak up against structural and racial violence

Our voices are heard as one that is uncivilized.

We turn to social media to speak out against racism

From the clicking of the mouse

Our voices are heard

In spaces they are not allowed.

Together we join voices in unity

As we stand in solidarity

To deconstruct the stereotypes and prejudices

Perpetuated by our superior complex shadow.

We refuse to fight racism with racist mentality,

Instead we preach the beauty of Blackness

That has been lost in the ideologies

Of colonialism, racialization and racism.

There is no shame in owning our Blackness

Our skin colour is permanent, not to be compared with Whiteness.

Removing the power from you to define us

We opened doors to let ourselves out---not in. 